\title{
A REVELAÇÃO ENCERROU-SE? REFLEXÕES A PARTIR DA “DEI VERBUM"
}

The revelation ended up? Reflections from "Dei Verbum"

\author{
Alexandre Patucci de Lima* \\ Pedro K. Iwashita**
}

\section{RESUMO}

Uma das afirmações teológicas clássicas assim se expressa: "A Revelação encerrouse com a morte do último apóstolo". A partir do Vaticano II e sua abordagem sobre a Revelação, este artigo questiona tal afirmação e propõe que, ao invés de afirmar uma "revelação encerrada", seja mais sensato expressar que "A plenitude da Revelação se manifestou em Cristo Jesus". Tal formulação abre perspectivas para se pensar a dinâmica histórica da Revelação em sua constituição, em sua manifestação na Igreja como autocomunicação de Deus que não cessa na história humana, bem como abre perspectivas para se pensar o processo de desenvolvimento dos dogmas, doutrinas e práxis cristãs, junto à necessidade de atualizá-los (repensá-los).

Palavras-chave: Revelação. Dogma.

\section{ABSTRACT}

One of the classic theological statements so expresses: "The Revelation ended with the death of the last apostle." From Vatican II on and its approach to Revelation, this article questions this claim and suggests that rather than assert a "closed revelation" is more sensible to express that "The fullness of revelation manifested in Christ Jesus." This formulation opens perspectives to think about the historical dynamics of Revelation in its constitution, in its manifestation in the Church as God's selfcommunication that does not cease in human history, and opens perspectives to think about the development process of dogmas, doctrines and Christian praxis, with the need to upgrade them (rethink them).

Keywords: Revelation. Dogma.

\footnotetext{
*Mestrando em Teologia Sistemática pela PUC-SP.

**Doutor em Teologia pela Universidade de Fribourg, Suíça. Professor da Faculdade de Teologia Nossa Senhora da Assunção, PUC/SP.
}

\begin{tabular}{|l|l|l|l|l|l|}
\hline Teocomunicação & Porto Alegre & v. 44 & n. 2 & p. 281-293 & maio-ago. 2014 \\
\hline
\end{tabular}




\section{Introdução}

Uma das afirmações clássicas da Teologia é a de que "a Revelação divina se encerrou com a morte do último apóstolo". Esta afirmação colocou uma dificuldade teológica, que suscitou diversas reflexões sobre a Revelação: "Como explicar a evolução do dogma?" Não é intuito deste trabalho fazer uma abordagem sobre as teorias que se estabeleceram a fim de explicar este processo de "evolução", mas, antes, procura-se aqui estabelecer que o próprio caráter dinâmico da Revelação está na base dessa evolução e com isso há a necessidade de expressar de outra forma aquela afirmação "clássica" da Teologia. Ao invés de afirmar que a "revelação se encerrou com a morte do último apóstolo", na linha do Vaticano II, é mais interessante propor que "A plenitude da Revelação manifestou-se em Jesus, e que esta Revelação continua a atuar na História", embora a Constituição dogmática Dei Verbum sobre a Revelação divina do Concílio Vaticano II não tematize explicitamente tal abordagem, dando, porém, a possibilidade de um ponto de partida para tal reflexão ao propor que a Revelação é "autocomunicação" de Deus.

Primeiramente será retomado suscintamente aqui o aspecto histórico da Revelação não só em sua constituição até a formação do Novo Testamento, mas em sua continuidade na história. Depois será dado um exemplo (a formação do cânon) sobre a dinamicidade da Revelação na História. A partir da constatação dessa dinamicidade da Revelação, se situará a evolução do dogma, e estas considerações nos permitirão também ressaltar que, em face à própria natureza da Revelação, há necessidade de sempre se "repensar e atualizar o dogma" e a mensagem cristã, ou seja, que a "inculturação" e a tal necessidade de se repensar e atualizar a mensagem cristã decorrem da própria natureza dinâmica e atuante da Revelação na História.

\section{A revelação em seu caráter histórico}

Como pressuposto para esta abordagem dinâmica da revelação, é importante ter em mente a consciência histórica moderna; a questão de que a verdade é algo inesgotável e sempre atingível por perspectivas humanas que se desenvolve no processo de conhecimento do ser humano. De fato, hoje, mais do que nunca, o homem tem noção da contingência histórica dentro do processo de "desenvolvimento" das sociedades. É dentro desse quadro que a Igreja também está inserida, e 
hoje percebe que acompanha este desenvolvimento histórico do homem. $\mathrm{O}$ avanço dos estudos exegéticos e teológicos, mesmo a partir do dado antropológico e cultural, deu conta que a própria Revelação se dá no processo histórico:

A implicação real, a interação entre as coisas e as pessoas não formam um continuum estático e indiferenciado, como se o mundo fosse um cristal isomórfico, eternamente iluminado e igual a si mesmo. O mundo é acontecimento, evolução, história; dentro dele a ação e a reação produzem mudança; à medida que essa mudança afeta o sujeito como cognoscente, se produz o conhecimento em sua variedade e multiplicidade. Igualmente na relação com Deus: à medida que trata de um Deus vivo e que sua ação sustenta o ser humano através do dinamismo cósmico e histórico, dentro da qual e a partir da qual este se abre à sua presença, também a relação reveladora acontece, se muda e se multiplica. A revelação, por ser revelação divina acolhida na subjetividade humana, intrinsecamente histórica, acontece necessariamente na mudança e no drama inerentes a toda história viva. ${ }^{1}$

É verdade que está mais que estabelecido que a Revelação deuse como processo histórico, seja na história do povo de Israel, seja na ação de Jesus e da Igreja nascente. Este processo envolveu a ação de Deus na história e a constante interpretação e reinterpretação do povo de Deus e da comunidade cristã primitiva aos "eventos" experimentados como eventos salvíficos. Inclusive a elaboração do Novo Testamento não se deu sem um processo de interpretação e reinterpretação do evento "Jesus" (inclusive e principalmente a partir da experiência da ressurreição) à luz do Antigo Testamento e do contexto vivido pelas comunidades cristãs primitivas.

Karl Rahner afirma que há uma "evolução" de pensamento no processo de formação da Escritura (que serve de "paradigma" para uma posterior "evolução do dogma"): "A evolução do dogma dentro da Escritura é, por isso, um caso modelo e garantido de toda evolução do dogma; um caso modelo que em si obriga aquele para quem a Escritura, em sua totalidade, é autêntico documento de fé". ${ }^{2}$ No entanto, é clássica

1 QUEIRUGA, Andrés Torres. Repensar a Revelação: a revelação divina na realização humana. São Paulo: Edições Paulinas, 2010, .p. 180.

2 "La evolución del dogma dentro de la Escritura es, por esto, el caso modelo y garantizado de toda evolucion del dogma; um caso modelo que em si obliga a aquel para quien la 
a declaração de que a Revelação se encerrou com a morte do último apóstolo, como se o processo da Revelação só se desenvolvesse no máximo até esse fato, como se fosse algo que aconteceu no passado.

Paralelo à afirmação de que a Revelação está encerrada, a Igreja percebeu que na sua história houve uma "história dos dogmas", e que surgiram afirmações de fé que não eram claras e afirmadas nos primeiros séculos. Eis como é posta a questão por Ladaria:

A evolução do dogma é inegável. Entre as afirmações dogmáticas da Igreja, há muitas que não se encontram literalmente na Escritura e até tratam de questões que, ao que parece, jamais preocuparam os autores do Novo Testamento. Aquilo que, num dado momento, foi objeto de uma definição dogmática nem sempre foi afirmado com a mesma clareza nas etapas anteriores. Mas há mais: a existência mesma do dogma significa que há uma evolução na formulação da fé; se esta não existisse, o dogma também não existiria. ${ }^{3}$

Se a Revelação se encerrou, como falar de "novas verdades" de fé que antes não eram expressas? Acontece que a perspectiva teológica que insistia no fato de que a "Revelação havia se encerrado" com a morte do último apóstolo, abordava a revelação numa perspectiva de "lista de verdades" que fora dada por Deus e que, portanto, não poderia ser "modificada"4. Nesse sentido a revelação "se encerrou". Mas o Vaticano II, na Constituição Dogmática Dei Verbum, preferiu tratar da Revelação como "autocomunicação de Deus à humanidade". ${ }^{5}$ Nesta perspectiva, em Cristo está a plenitude de Revelação pelo fato de nele Deus manifestar-

Escritura, em tanto totalidad, es autentico documento de fe" RAHNER, Karl. Reflexiones en torno a la evolución Del dogma. In: Escritos de Teologia. Tomo IV. Madrid: Taurus ediciones, 1963, p. 18.

3 LADARIA, LUIS F. O que é um dogma? O problema do dogma na teologia atual. In: Problemas e perspectivas de Teologia dogmática. São Paulo: Edições Loyola, p. 94.

4 Referindo-se aos teólogos do séc. XIX e início do séc. XX, Gabriel Moran afirma: "Há quase perfeita unanimidade entre escritores da época em definir a revelação como a manifestação da verdade através da locução divina (locutio Dei) [...] a revelação é tomada no sentido de instrução das verdades à criatura racional, verdades essas que ela é incapaz de alcançar somente pela razão" MORAN, Gabriel. Teologia da Revelação. São Paulo: Herder,1969, p. 19.

5 "Pela Revelação Divina quis Deus manifestar-se e comunicar-se a si mesmo" (Dei Verbum 6). Já no parágrafo 2, a Dei Verbum afirmava: Aprouve a Deus, na sua bondade e sabedoria, revelar-se a si mesmo e dar a conhecer o mistério de sua vontade (cf. Ef 1,9), mediante o qual os homens, por meio de Cristo, Verbo encarnado, têm acesso no Espírito Santo ao Pai e se tornam participantes da natureza divina (cf. Ef 2, 118; 2 Pd 1,4)" 
se plenamente doando-se e fazendo-se homem como nós. O ápice da autocomunicação de Deus está no fato da Encarnação (entendida não só como o nascimento de Jesus, mas toda sua vida). Nesse sentido, a Revelação em Jesus Cristo é insuperável, pois é manifestação do ápice daquilo que deve constituir a relação do homem com Deus e de Deus com o homem. No entanto, esta autocomunicação de Deus, que foi plena em Jesus, não ficou no passado, ela é justamente o desígnio salvífico de Deus atualizado pelo Espírito, no qual os homens são chamados a "participar da natureza divina" (2Pd 1,4; DV 2). Então, nesta perspectiva a Revelação de Deus é um processo dinâmico que continua na Igreja!

A Revelação de Deus, como já o dissemos, alcançou seu ponto culminante e a sua plenitude, na consciência do Senhor glorificado. De acordo com a fé católica, aquela pessoa, Jesus Cristo, continua a viver num modo novo de tempo e numa maneira mais elevada de vida. Ora, sendo isto verdade, então a revelação continua a ocorrer, isto é, o Pai ainda fala a Palavra, a qual ressoa na humanidade de Cristo e no mundo unido a Cristo. ${ }^{6}$

Pode-se dizer então que pode haver uma mudança de perspectiva na maneira de abordar a questão anteriormente formulada (A revelação encerrou-se com a morte do último apóstolo?). Nesta nova perspectiva não se fala de "Revelação encerrada", mas de "plenitude de revelação", pois em Jesus se manifesta a plenitude da presença de Deus na humanidade, e ao mesmo tempo uma resposta plena e definitiva do homem Jesus à vontade de Deus. Com isso, na relação entre Deus e o homem (seja na atuação de Deus em salvar e redimir, seja na resposta do homem de entrega a Deus) nada há de se acrescentar naquilo que em Jesus se manifestou e revelou (Em Jesus revela-se a ação do Pai, e a entrega e doação do homem), ${ }^{7}$ e que se torna confirmado na ressurreição, onde também se manifesta o caráter definitivo desta união do homem com Deus através da glória de Jesus ressurreto. De fato, em Jesus

todo o fundamental está nele patente; nenhuma dimensão essencial na relação Deus-homem poderá ser acrescentada ao revelado em sua pessoal relação com o Pai. Não cabe na história nem maior

\footnotetext{
MORAN, Gabriel. Teologia da Revelação. São Paulo: Herder,1969, p. 139.

A Gaudium et Spes fala de Jesus como "modelo de humanidade": "Cristo, novo Adão na própria revelação do mistério do Pai e do seu amor, revela o homem a si mesmo e descobre-lhe a sua vocação sublime" GS 22.
} 
transparência à presença de Deus nem maior entrega à sua vontade salvadora. $^{8}$

A Revelação plena em Cristo (como manifestação da atuação salvífica de Deus e resposta humana) não anula o fato de que Deus continua a agir, a salvar e a dialogar com a humanidade nos tempos atuais. A autocomunicação de Deus é a revelação plena de Deus em Jesus para a humanidade "hoje", ou seja, "hoje" a Igreja anuncia esta autocomunicação de Deus, puro amor, e não só anuncia, como ela se torna realidade pela ação do Espírito: Deus continua a "doar-se" e "comunicar-se" à humanidade (sua autocomunicação, que constitui para nós a salvação: comunhão com Ele e todas as coisas no amor); então a revelação é algo sempre atual, atuante! "O ser de Deus é um ser revelador, portanto, ele não para de se revelar". ${ }^{9}$

Se não compreendermos a Cristo como quem está agora revelando Deus ao homem, a fé estará fadada a se tornar (a despeito dos nossos protestos em contrário) uma aceitação racional de fatos passados e de ensinamentos presentes externos à atividade adoradora-santificadora que acontece agora. Mas a fé não é dirigida a uma mensagem, mas a Deus que ressuscitou Cristo, e isto não é um evento passado, mas um acontecimento sempre presente e continuo. ${ }^{10}$

O caráter dinâmico da revelação funda-se justamente no fato de que o ser humano é ser histórico, e de que também só se pode falar de "revelação divina" a partir do ato humano de expressar esta "revelação" a partir de sua experiência interior de fé (iluminada pelo Espírito) em que o ser humano "lê" na história as ações de Deus e seu significado salvífico. Esse processo se dá no âmbito de uma comunidade de fé, que "garante" a legitimidade desta "interpretação", e "responde" a partir da fé a essa "revelação" (comunidade cuja origem remonta à comunidade apostólica). Esta "Revelação" se constitui num processo de "interação humana", a partir da experiência interior que iluminada pela fé da comunidade aponta os desígnios salvíficos de Deus dentro de um contexto histórico. A revelação não é uma "lista de verdades", mas se

8 QUEIRUGA, Andrés Torres. Repensar a Revelação: A revelação divina na realização humana. São Paulo: Edições Paulinas, 2010, p. 257.

9 BOTTIGHEIMER, Christoph. Manual de Teologia Fundamental: a racionalidade da questão de Deus e da Revelação. Petrópolis: Vozes, 2014, p. 149.

${ }^{10}$ MORAN, Gabriel. Teologia da Revelação. São Paulo: Herder,1969, p. 141. 
constitui nesta dialética do diálogo-autodoação de Deus à humanidade que vai compreendendo cada vez mais algo de Deus e Sua "Vontade" que se manifestou na história do povo, e plenamente em Cristo. Citando o parágrafo quarto da Dei Verbum, o Catecismo da Igreja Católica diz:

A economia cristã, portanto, como aliança nova e definitiva, jamais passará, e já não há que esperar nenhuma nova revelação pública antes da gloriosa manifestação de Nosso Senhor Jesus Cristo. Todavia, embora a revelação esteja terminada, não está explicitada por completo; caberá à fé cristã captar gradualmente todo o seu alcance ao longo dos séculos. ${ }^{11}$

Embora o catecismo fale de "revelação terminada", pode-se entender aqui que se quer expressar a "definitividade" da Revelação em Cristo enquanto "Aliança" nova e definitiva, que necessita ser "explicitada" ao longo dos séculos. Deve-se deixar claro que aquilo que há de "implícito" na Revelação definitiva em Jesus Cristo não diz respeito apenas às fórmulas dogmáticas que, depois, por uma dedução lógica e intelectual, serão explicitadas. O que está "implícito" nessa Revelação fundante e definitiva em Cristo é tudo aquilo que a partir Dele é passível de ser vivido na história (como relação com Deus, com o mundo, com os outros e consigo mesmo) em seus contextos próprios, e que torna o homem capaz de, a partir destas experiências históricas (que "abrem" sua consciência e intelecto para novas compreensões da realidade), apreender e compreender algo mais daquela Revelação definitiva (Aliança), que por ser histórica, se desdobra na História do homem.

A revelação é a ação de Deus na história que um povo e comunidade interpretam na fé. A própria Escritura já é interpretação. A própria resposta da fé pertence ao conteúdo mesmo da Revelação. A Revelação atinge sua plenitude, seu sentido, sua realização, na fé que a acolhe. A fé é, sob o aspecto cognitivo, um conhecimento interpretativo, marcado pelas condições históricas do sujeito e da comunidade que crê. ${ }^{12}$

${ }^{11}$ CATECISMO DA IGREJA CATÓLICA. São Paulo: Vozes, 1999. n. 66.

${ }^{12}$ LIBANIO, João Batista. Teologia da revelação a partir da modernidade. São Paulo: Vozes, p. 404. 
Convém lembrar que mesmo a "Revelação definitiva em Jesus Cristo" não deixou de ser mediada pela historicidade do próprio homem Jesus e da comunidade cristã primitiva que "interpretou" sob a luz do Espírito esta realidade salvífica de revelação. Sendo assim, não há uma "revelação definitiva pura" pairando no ar! Ela se encontra na Igreja que incessantemente acolhe na fé os testemunhos da Tradição (escrita e oral). E é nessa dialética de receber esta Tradição e acolhê-la na fé que se dá a Revelação, pois foi assim que ela se deu na história da Salvação. Como diz Schillebeeckx: "Experiência e compreensão da revelação entram também de maneira constitutiva no processo da Revelação", ${ }^{13}$ pois não há Revelação sem acolhida já reflexiva do ser humano, a partir de sua experiência de fé (não há também experiência pura que não seja refletida e interpretada!). Neste processo que perdura na Igreja, a Tradição Apostólica (oral e escrita) é normativa como ponto de referência daquela plenitude da Revelação manifestada em Jesus por ser testemunhada e anunciada pelos Apóstolos. Dessa autoridade apostólica deriva o caráter normativo das Escrituras do Novo Testamento: chave de interpretação do Antigo Testamento, e também de todo desenvolvimento da Tradição eclesial dentro deste processo dinâmico da revelação na Igreja que a leva a compreender sempre mais, por novas perspectivas, e, consequentemente, novas compreensões e afirmações, a realidade salvífica e Deus, mesmo que não cessa de atuar na História. A própria comunidade, como comunidade "Apostólica" (que vem dos Apóstolos acolhendo a Tradição escrita e oral) se torna, a partir disso, "normativa", através do Magistério, garantindo, atualizando e interpretando, a revelação na história, sob influxo desta revelação viva e atuante por ação do Espírito.

\section{Um exemplo: A formação do cânon: verdade revelada?}

O caráter dinâmico desta revelação na Igreja se faz perceptível de diversas maneiras, ainda que por muito tempo não tenha sido teoricamente tematizada pela teologia. Um exemplo disso pode-se perceber na formação do Cânon bíblico. Pode-se dizer que a "definição" do Cânon é um ato "dogmático" da Igreja. ${ }^{14}$ No entanto a lista do Cânon

${ }^{13}$ SCHILlEBEECKX, E. História humana, revelação de Deus. São Paulo: Paulus, 1989, p. 63.

${ }^{14}$ Cf: SESBOUE, B. História dos dogmas: o Deus da salvação. Vol. 1. São Paulo: Loyola, 2002, p. 58-65. 
não ficou definida com a morte do último apóstolo. (João não deixou à Igreja a lista do cânon...). A escolha do cânon foi muito posterior, e, no entanto, percebe-se que o "fundamento" desta escolha está justamente constituído na "autoridade apostólica" destes escritos afirmada pela Igreja assistida pelo Espírito. Por um lado, a Igreja não escolhe aleatoriamente estes livros, mas ela parte "da Tradição que recebeu", não sem tensões! Há um fundamento apostólico para esta escolha que se encontra naquilo que é "anterior à morte do último apóstolo", a saber, os ensinamentos destas escrituras, de autoridade apostólica. Por outro lado a Igreja "define" algo novo de fundamental importância, que não estava ainda definido. Pode-se dizer que houve aí um "eco" da "revelação" dinâmica da Palavra de Deus (que vai além do texto escrito), não no sentido de que uma "verdade" nova foi dita sobre a salvação, mas no sentido de que o Espírito iluminou a Igreja para que nela os homens discernissem uma "verdade", a saber, o cânon da Escritura a partir da Tradição, justamente para garantir uma justa compreensão da realidade definitiva da salvação! As afirmações dogmáticas da Igreja são sempre em vista à compreensão mais plena desta realidade salvífica revelada em Cristo. Não só na formação do Cânon verificamos este processo, mas também na construção dos Símbolos apostólicos, da constituição hierárquica da Igreja, das doutrinas, da liturgia, dos dogmas etc.

Vê-se, portanto que a Igreja proclama uma verdade (no caso, sobre o cânon) que não estava tematizada nem explícita e nem implicitamente na Tradição. Tal verdade não foi apenas fruto de uma reflexão dedutiva a partir de outras verdades reveladas, a fim de explicitar uma verdade implícita. Ela proclamou uma "verdade nova", pois ela não era clara no século I e II, por exemplo, mas verdade esta que não acrescenta nada à definitividade da Revelação em Cristo Jesus. Porém pode-se dizer que é uma "verdade revelada", que se torna "normativa", revelada não "com a morte do último Apóstolo" literalmente falando, mas sob a autoridade apostólica, no interior da Igreja, porque a Revelação é processo dinâmico. ${ }^{15}$

No VIII Concílio de Constantinopla, em seu primeiro cânone, talvez se encontre uma afirmação mais explícita desta "consciência" da Igreja de uma "revelação dinâmica" e "atual":

\footnotetext{
15 “A presença da Revelação na tradição oral da Igreja permite-lhe reconhecê-la neste ou naquele livro bíblico.” Cf. THEOBALD, C. Do Vaticano I a 1950: Revelação, fé e razão, inspiração, dogma e magistério infalível. In: SESBOUE, B. História dos dogmas: a palavra da salvação. Vol. 4. São Paulo: Loyola, 2006, p. 236.
} 
Se quisermos caminhar sem tropeços pelo caminho reto e régio da justiça divina, devemos conservar as definições e ensinamentos dos santos padres como se fossem lâmpadas sempre acesas e iluminadoras de nossos passos, que são segundo Deus. Por isso, plenamente persuadidos de que esses ensinamentos, segundo o pensamento do sapientíssimo Dionisio, constituem uma segunda Palavra de Deus, não hesitamos em aplicar-lhes as palavras de Davi: Ó mandamento do Senhor é luminoso e ilumina os olhos', e 'Tua luz é uma lâmpada a iluminar meus caminhos' $[\ldots]^{16}$

É interessante notar nesta citação que os padres conciliares consideram os ensinamentos dos santos padres autorizados pela Igreja como "segunda Palavra de Deus", aplicando-lhes citações da Escritura! Pode-se falar aqui de um reconhecimento de que Deus "fala" na Igreja, e que, portanto, a Revelação divina é um processo atual e constante, pois Ele sempre faz com que a Igreja "perceba" e "apreenda" sempre algo "novo" das realidades e dos mistérios divinos. Diz São Gregório Magno que "As Palavras Divinas crescem juntamente com quem as lê"; ${ }^{17}$ o catecismo da Igreja também afirma que "Graças à assistência do Espírito Santo, a compreensão tanto das realidades como das palavras do depósito da fé pode crescer na vida da Igreja". ${ }^{18}$ Já no Evangelho de João se diz: "Mas o Paráclito, o Espirito Santo que o Pai enviará em meu nome, vos ensinará tudo e vos recordará tudo o que eu vos disse" (Jo 14,26).

Diante das reflexões acima, percebe-se que a questão da "evolução dos dogmas" na verdade "não é exclusivo das formulações dogmáticas, mas é típico da tradição no seu conjunto, enquanto transmissão da revelação em toda a vida da Igreja; e nessa transmissão há sempre uma evolução". ${ }^{19}$ Evolução (ou desenvolvimento) que não é só intelectual, pois implica também aspecto emocional, afetivo, sentimental, e influi na liturgia, nas devoções e piedades populares, no "direito", pois o desenvolvimento histórico influencia no modo como o homem se situa

${ }^{16}$ CONCÍLIO CONSTANTINOPOLITANO VIII. In: SKRZYPCZAK, Otto. Documentos dos primeiros oito Concílios Ecumênicos. Porto Alegre: Edipucrs, 2000, p. 116.

${ }^{17}$ SÃO GREGÓRIO MAGNO. Homiliae in Ezechielen. Apud. BENTO XVI. Verbum Domini. São Paulo: Paulinas, p. 61.

${ }^{18}$ CATECISMO DA IGREJA CATÓLICA. São Paulo: Vozes, 1999. n. 94.

${ }^{19}$ LADARIA, LUIS F. O que é um dogma? O problema do dogma na teologia atual. In: Problemas e perspectivas de Teologia dogmática. São Paulo: Edições Loyola, p. 94. 
em seu contexto, no mundo diante dos outros e de Deus, e isso em todos aspectos pessoais (racionais, emotivos, etc.).

Em sua Tradição, a comunicação que o Pai faz de si através do Logos no Espírito Santo continua sempre presente na Igreja sob múltiplas formas: em sua Palavra e suas obras, em sua liturgia e sua oração bem como na plenitude de sua vida (DV 8). As definições dogmáticas não são mais que um elemento no interior desta tradição muito mais abrangente. ${ }^{20}$

A própria constituição da revelação como algo que se dá na história está no fundamento do fato de se poder falar de desenvolvimento ou evolução do dogma. "Se a revelação chega até nós pela história e na história, como acontecimento, segue-se que esse acontecimento está submetido às condições da história"; ${ }^{21}$ por isso, afirma ainda Latourelle sobre a revelação:

Mesmo firmando que ela vem de Deus, será necessariamente recebida nas categorias de uma época, de uma mentalidade. Portanto, como poderá entrar na história a não ser mutilada, deformada, exposta a todas as vicissitudes da história que bem conhecemos. Parece ser essa necessariamente a situação de uma revelação histórica. ${ }^{22}$

Desta condição da revelação na história pode-se afirmar que “Também o progresso da revelação está ligado à história". ${ }^{23}$ Tudo isto fundamenta a necessidade de que a revelação definitiva em Cristo (enquanto plenitude da autocomunicação de Deus à humanidade) seja compreendida cada vez mais a partir da experiência de fé em contextos próprios a partir da experiência da comunidade primitiva com suas categorias próprias. $\mathrm{O}$ modo como se constitui a Revelação pede a "inteligência da fé" para que seja compreendida para ser anunciada, e, ao mesmo tempo, fundamenta o caráter de processo "evolutivo" na história da Tradição eclesial e do dogma. Isso se dá também porque a Revelação é processo dinâmico, pois o Espírito é quem conduz a Igreja à plenitude da verdade.

${ }^{20}$ COMISSÃO TEOLÓGICA INTERNACIONAL. A interpretação dos dogmas. SEDOC, Petrópolis: Vozes, v. 23, n. 222, p. 201, set.-out. 1990.

${ }^{21}$ LATOURELLE, Rene. Teologia da Revelação. São Paulo: Edições Paulinas, 1981, p. 466.

${ }^{22}$ Ibidem, p. 167.

${ }^{23}$ Ibidem, p. 464. 


\section{Conclusão}

Pode-se afirmar, portanto, que todo desenvolvimento "reflexivo" e "prático" da fé ao longo da história da Igreja se dá sob o influxo da Revelação! Tal desenvolvimento não é apenas um desdobramento lógico, intelectual, afetivo, prático e natural (embora tais aspectos influenciem) a partir de uma revelação encerrada há quase 2.000 anos, mas é o desenvolvimento "vivo", na experiência da fé iluminada pelo Espírito no seio da comunidade com suas tensões próprias e que Deus "respeita", e onde age.

Independente das teorias formuladas na história da teologia e que tentam explicar o desenvolvimento dos dogmas (que nos ajudam a compreender os aspectos históricos desse desenvolvimento), o fundamento teológico disso está na própria natureza da Revelação. Nesse sentido é próprio mudar a perspectiva em relação à antiga afirmação de que a Revelação se encerrou com a morte do último apóstolo. Tal mudança de perspectiva não muda a essência do que se afirmava, mas abre perspectivas para se pensar e viver a Revelação divina em face da consciência histórica atual de maneira dinâmica e criativa, justificando a necessidade de que a fé seja também em seus dogmas e doutrinas atualizadas para que seja bem compreendida e vivida: Isto é um imperativo a partir da própria natureza da Revelação! Nesse sentido, ser fiel à Tradição não pode ser nunca simplesmente repetir ensinamentos! Isso não seria "Tradição", mas "traição".

Se a "evolução do dogma" (e da tradição eclesial) é algo "natural" e "sobrenatural" (atuação incessante da autocomunicação divina que constitui a Revelação), não se pode dispensar a Igreja de estar aberta à voz do Espírito, de sempre buscar compreender de novo aquilo que lhe fora transmitido para anunciar no hoje da história, tendo a capacidade de aprender aquilo de novo que pode se abrir a ela a partir de novos horizontes históricos. Assim, para tornar a fé atuante e atual para o homem de hoje, a Igreja precisa tanto agir e testemunhar a caridade, como também a verdade, pensada a partir da vida, e da História, vista como História da Salvação. Neste processo todo cristão tem seu lugar porque a Revelação só se constitui na acolhida de fé dos cristãos em comunidade. Não há revelação sem a acolhida da fé de cada cristão. É por isso que a Igreja sempre ouve o "sensus fidelium", o "senso dos fiéis", pois a Revelação é processo dinâmico no seio do Povo de Deus. Nesse processo todo cristão está inserido, pois, como diz Santo 
Agostinho, "Todo aquele que crê reflete, crendo medita, e meditando crê... Uma fé sobre a qual já não se reflete não é mais fé". ${ }^{24} \mathrm{E}$ como comunidade, esta reflexão sobre a fé a partir da experiência atual da autocomunicação de Deus, está inserida na Revelação Divina, que não acontece sem a participação humana ao longo da história!

\section{Referências}

BENTO XVI. Verbum Domini. São Paulo: Paulinas, [s./d.].

COMISSÃO TEOLÓGICA INTERNACIONAL. A interpretação dos dogmas. In: SEDOC, Petrópolis: Vozes, v. 23, n. 222, set.-out. 1990.

CATECISMO DA IGREJA CATÓLICA. São Paulo: Vozes, 1999.

MORAN, Gabriel. Teologia da Revelação. São Paulo: Herder, 1969.

LADARIA, Luis F. O que é um dogma? O Problema do dogma na teologia atual. In:

NEUFELD, Karl H. Problemas e perspectivas de teologia dogmática. São Paulo: Loyola, 1993.

LATOURELlE, Rene. Teologia da Revelação. São Paulo: Edições Paulinas, 1981.

LIBANIO, João Batista. Teologia da revelação a partir da modernidade. São Paulo: Vozes, [s./d.].

QUEIRUGA, Andrés Torres. Repensar a Revelação: a revelação divina na realização humana. São Paulo: Edições Paulinas, 2010. p. 180.

RAHNER, Karl. Reflexiones em torno a la evolución del dogma. In: Escritos de Teologia. Taurus ediciones, Madrid, 1963. Tomo IV.

SCHILLEBEECKX, E. História humana, revelação de Deus. São Paulo: Paulus, 1989.

SESBOUE, B. História dos dogmas: o Deus da salvação. São Paulo: Loyola, 2002. Vol. 1.

SESBOUE, B. História dos dogmas: a palavra da salvação. São Paulo: Loyola, 2006. Vol. 4.

SKRZYPCZAK, Otto. Documentos dos primeiros oito Concílios Ecumênicos. Porto Alegre: Edipucrs, 2000.

${ }^{24}$ SANTO AGOSTINHO, apud SCHILLEBECKX, Edward. Revelação e Teologia. São Paulo: Edições Paulinas, 1968, p. 350. 